\title{
Abordagens metodológicas utilizadas no processo de ensino- aprendizagem de Anatomia Humana nos últimos 50 anos e aplicações aos graduandos em Fisioterapia
}

\author{
Methodological approaches used in the teaching-learning process of Human \\ Anatomy in the last 50 years and applications to undergraduate students in \\ Physiotherapy
}

\author{
Caio Ramon Queiroz (D) https://orcid.org/0000-0002-8340-8217 \\ Centro Universitário de Volta Redonda (UniFOA) \\ E-mail: caioramoncra@hotmail.com
}

André Barbosa Vargas (iD https://orcid.org/0000-0002-8340-8217

Centro Universitário de Volta Redonda (UniFOA)

E-mail: andre.vargas@foa.org.br

Carlos Alberto Sanches Pereira (iD https://orcid.org/0000-0002-6227-6198

Centro Universitário de Volta Redonda (UniFOA)

E-mail: sanches68@gmail.com

\section{Resumo}

A disciplina de Anatomia Humana $(\mathrm{AH})$ é considerada um dos pilares da matriz curricular que compõem o ciclo básico das graduações na área da saúde, servindo de subsídio para outros componentes curriculares, exatamente como acontece na graduação em Fisioterapia. Entretanto, a literatura aponta dificuldades durante a trajetória da disciplina, pois se trata de um conteúdo extenso e complexo. Neste sentido, este estudo visa identificar quais as abordagens metodológicas utilizadas no processo de ensino-aprendizagem em $\mathrm{AH}$ e suas aplicações para graduandos em Fisioterapia. Para tanto, foi realizado uma revisão integrativa da literatura, utilizando bases de dados eletrônicas - Google Acadêmico, SciELO e Periódicos Capes - aplicando as seguintes palavras-chave: "Ensino de Anatomia Humana", "Anatomia Humana e Educação" e "Anatomia Humana". Foram encontrados 1764 artigos dos quais após avaliação, leitura do título e do resumo, 179 foram selecionados. Em seguida, procedemos à leitura e coleta de informações que apontaram uma diversidade de tecnologias educacionais e metodologias ativas voltadas ao ensino de Anatomia Humana. Principalmente, nos últimos 20 anos, constatando a importância de inovações constantes no processo de ensinoaprendizagem. No entanto, em sua maioria, os estudos investigaram propostas de tecnologias e metodologias educacionais, novas e/ou adaptadas, aos cursos da área da saúde e, uma pequena parcela de estudos direcionada a Fisioterapia.

Palavras-chave: Fisioterapia. Ensino. Métodos Didático-Pedagógicos.

\section{Abstract}

The discipline of Human Anatomy $(\mathrm{AH})$ is considered one of the pillars of the curriculum that make up the basic cycle of undergraduate courses in the health area, serving as a subsidy for other curricular 
components, exactly as it happens in the undergraduate course in Physiotherapy. However, the literature points out difficulties during the course of the discipline, as it is extensive and complex content. In this sense, this study aims to identify which methodological approaches are used in the teachinglearning process of the HA discipline and its applications for undergraduate students in Physiotherapy. For this purpose, an integrative literature review was carried out, using electronic databases - Google Scholar, SciELO, and Capes Periodicals - applying the following keywords: "Teaching of Human Anatomy", "Human Anatomy and Education", and "Human Anatomy" . A total of 1764 articles were found, of which, after evaluating the title and abstract, 179 were selected. Then we proceeded to read and collect information that pointed out a diversity of educational technologies and active methodologies aimed at teaching Human Anatomy. However, a small portion of studies was directed to the Physiotherapy course. In addition, most studies have investigated proposals for educational technologies and methodologies, new and or adapted, to courses in the health field. Mainly, in the last 20 years, realizing the importance of constant innovations in the teaching-learning process.

Keywords: Physiotherapy. Teaching. Didactic-Pedagogical Methods.

\section{Introdução}

A disciplina de Anatomia Humana (AH) é considerada um dos pilares da matriz curricular das graduações na área da saúde (VERRI et al., 2011), compondo o ciclo básico de disciplinas que subsidia a construção de conhecimentos de outros componentes curriculares específicos à cada curso (ARRUDA; SOUSA, 2014), exatamente como acontece na graduação em Fisioterapia.

Entretanto, a complexidade e a extensão dos conteúdos abordados nesse componente curricular, podem vir a gerar complicações no processo de aprendizagem e na trajetória acadêmica. Dentre as adversidades relatadas na literatura, as nomenclaturas exóticas e não usuais, além da dificuldade de correlacionar o conteúdo teórico a prática clínica, promovem outros conflitos que transportam ao sentimento de desmotivação do ambiente estudantil e consequentemente, a falta ou perda do interesse (CROCHEMORE; MARQUES, 2017; SILVA et al., 2018).

Mediante as dificuldades e ao avanço constante da tecnologia, novas abordagens emergem determinadas a viabilizar o processo de aprendizagem, a reestruturação e edificação do ensino, explorando Tecnologias Educacionais, Metodologias Ativas, Produtos Educacionais e Tecnologias da Informação e Comunicação (TIC) (OLIVEIRA; WOLKERS, 2020) para aprimorar e melhorar o processo de ensino aprendizagem.

Não obstante ao crescimento exponencial de novos recursos didáticos, o ensino de $\mathrm{AH}$ ainda se encontra estreitamente inerente ao cadáver humano, sendo o recurso mais utilizado durante as aulas (OLIVEIRA; WOLKERS, 2020). Apesar de estudos apontarem certa dificuldade na utilização e manutenção de peças cadavéricas como, por exemplo, dificuldades de doações, para renovação das mesmas. Seu custo financeiro elevado, deterioração pelo uso constante - por vezes até inviabilizando o estudo, além de ser um obstáculo para alguns acadêmicos que apresentam repulsa visual, tátil e olfativa (COSTA; COSTA; LINS, 2012).

Todavia, na perspectiva de fomentar a autonomia da aprendizagem e de aproximar os discentes do processo de construção do ensino-aprendizagem, é que a adoção de metodologias ativas e novas tecnologias de ensino vem ganhando espaço, transcendendo a passividade do desenvolvimento do conhecimento, carreando a integração e familiarização acerca do que é disponibilizado e assim, possibilitando que 
sua voz seja ativa durante toda a formação (STRINI; STRINI; BERNARDINO JÚNIOR, 2020).

Neste sentido, o ensino de anatomia tem sofrido reformulações em sua práxis no intuito de aprimorar e promover seu entendimento e de suas aplicações conceituais (SILVA et al., 2018). Diante deste panorama, e norteando o desenvolvimento desta pesquisa foram avaliadas quais as abordagens utilizadas no processo de ensinoaprendizagem de Anatomia Humana nos últimos 50 anos e suas aplicações para graduandos em Fisioterapia.

\section{Metodologia}

O presente estudo trata-se de uma revisão integrativa da literatura a qual foi realizada por meio de levantamento bibliográfico nas bases de dados eletrônicas, Biblioteca Eletrônica Científica (SciELO), Periódicos Capes e Google Acadêmico no período de janeiro a março de 2021. Em seguida, no período de abril a outubro de 2021, procedeu-se a seleção, leitura avaliativa e coleta de dados dos textos selecionados. O espaço temporal utilizado na busca por artigos foi entre 1970 a 2020. Para esta busca, os descritores utilizados foram "Ensino de Anatomia Humana", "Anatomia Humana e Educação", e "Anatomia Humana"; (Teaching Human Anatomy, Human Anatomy, Education and Human Anatomy).

Para a seleção e avaliação dos estudos, foram firmados os critérios de inclusão (estudos que abordaram a inserção de alternativas metodológicas no processo de ensino-aprendizagem de Anatomia Humana) e exclusão (estudos que não abordaram tal inserção). Todavia, alguns estudos como, por exemplo, revisões de literatura e estudos de opinião relevantes as temáticas foram utilizados na fundamentação teórica e discussão. Para a inclusão dos estudos na coleta de dados, utilizamos dois critérios: 1) estudos que abordassem o ensino em anatomia humana e; 2) estudos que abordassem e ou avaliassem metodologias de ensino para Anatomia Humana. Para os critérios de exclusão utilizamos: 1) estudos específicos em anatomia que não se aplicavam ao processo de ensino; 2) estudos publicados em anais de eventos científicos, dissertações, teses e artigos duplicados.

Após a seleção e leitura dos artigos, procedemos a análise das informações e a coleta de dados de cada artigo selecionado. Desta forma, os estudos foram agrupados em duas categorias: I) estudos que aplicaram metodologia(s) já existente(s) para o ensino de anatomia humana, II) estudos que propuseram novas metodologia(s) para o ensino de anatomia humana e III) estudos que desenvolveram e aplicaram novas tecnologias para o ensino de Anatomia Humana. Para todos os artigos selecionados, as informações foram agrupadas em uma planilha do Microsoft Excel para quantificação dos seguintes dados: Autor, Ano, Título, Objetivo, Metodologia, Cenário, Resultado, Aplicação e Avaliação. Além disso, no intuito de compreender e poder avaliar a trajetória do ensino de Anatomia Humana no período de 1970 a 2020, as publicações foram agrupadas em décadas.

\section{Resultados}

Com a aplicação da estratégia adotada para a coleta de dados, foram encontrados 1764 artigos, distribuídos da seguinte forma: em (02) dois no SciELO, (09) nove no Periódicos Capes e 1753 no Google Acadêmico. Em seguida, os artigos foram 
avaliados pela leitura dos títulos e resumos que se enquadrassem na temática do estudo, o que resultou na seleção de 192 publicações, com 1572 estudos excluídos. Ao final deste processo, ainda foram excluídas mais (04) quatro publicações por serem duplicadas e (09) nove por não se encaixam nos critérios de inclusão, resultando em um total de 179 artigos, os quais, foram lidos na íntegra pelos autores (Figura 1).

Figura 1 - Fluxograma referente as etapas do processo de busca de dados para a avaliação das publicações relacionadas ao ensino de Anatomia Humana.

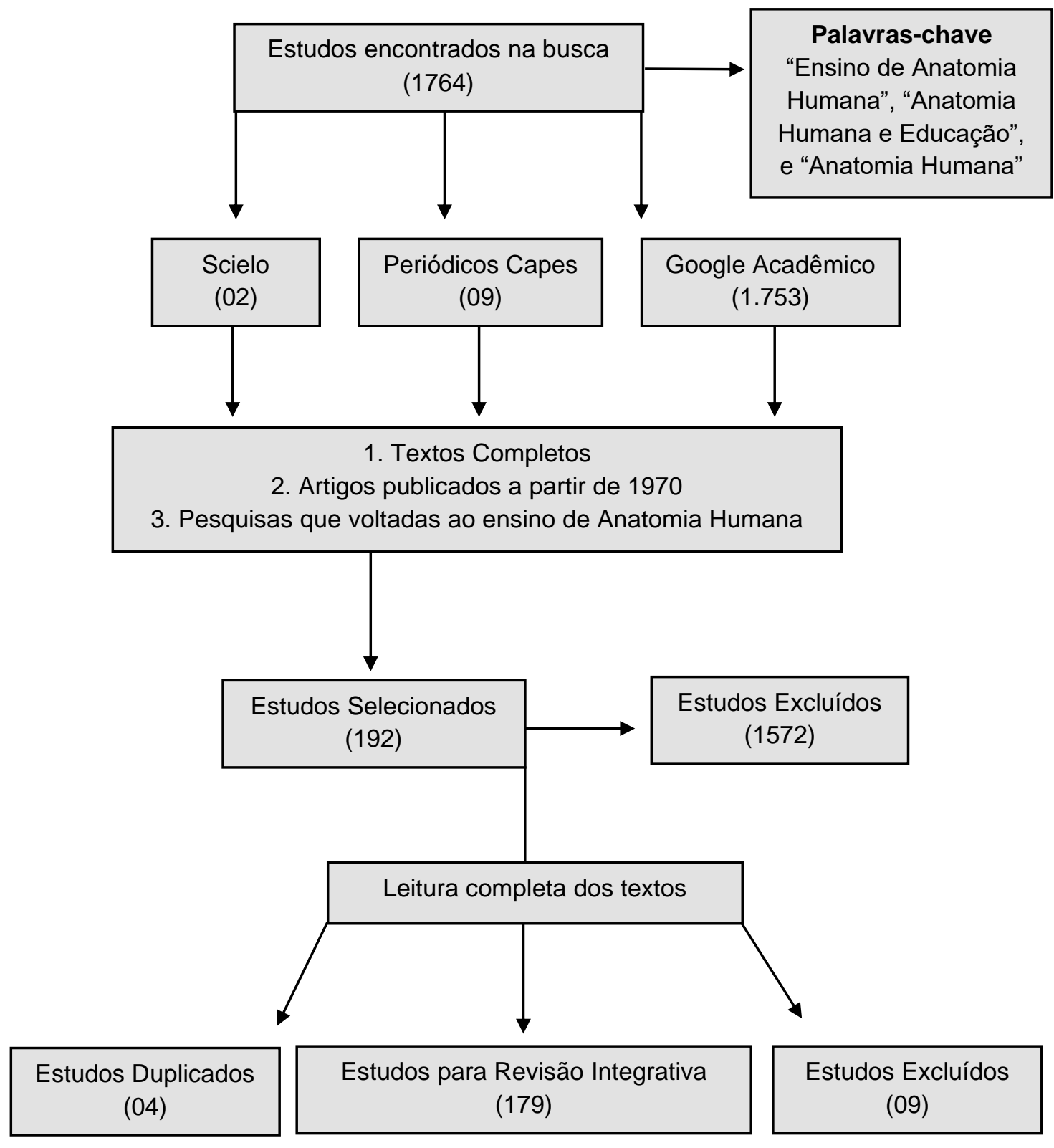

Fonte: Elaborado pelos autores (2021).

A distribuição das publicações apontou um crescimento de pesquisas e propostas metodológicas com novas ferramentas educacionais aplicadas ao ensino de Anatomia Humana. Um crescimento substancial nos últimos 20 anos (Figura 2). Ao longo do período analisado, 1970 a 2020, as décadas de 2000/2009 e 2010/2019 concentraram 
o maior número de publicações, enquanto a década de 1970/1979 apresentou menor produção.

Figura 2 - Número de publicações distribuídas no período de 1970 a 2020 relacionadas ao ensino de Anatomia Humana.

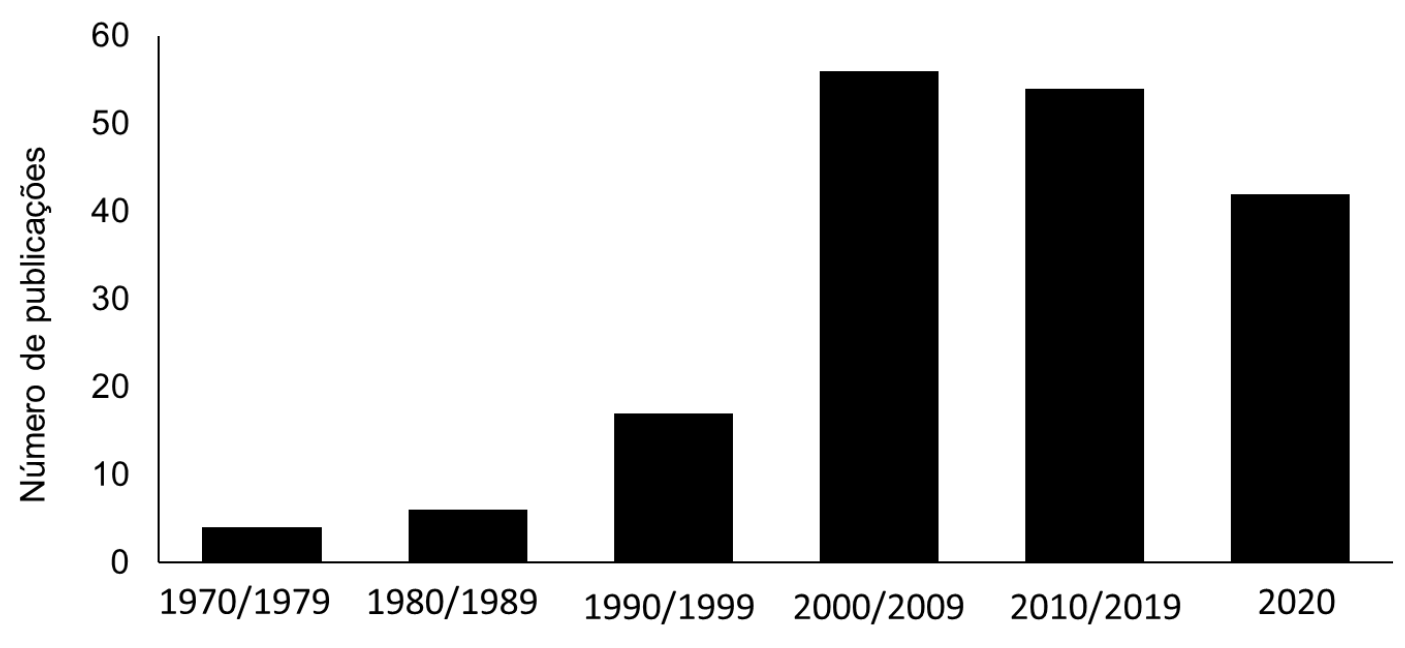

Décadas

Fonte: Elaborado pelos autores (2021)

Ao avaliar a distribuição e os objetivos das pesquisas, pode-se observar o constante crescimento das publicações com propostas de novos métodos e ferramentas de ensino que visam auxiliar a práxis docente e facilitar o processo de ensino aprendizagem de Anatomia de modo geral. Observa-se a partir do ano 2000, um crescimento constante das publicações. Tais pesquisas com um enfoque cada vez maior na validação de métodos e técnicas de ensino, e com isso, gerando possibilidades para experimentações e avaliações de casos em distintos cenários (Figura 3).

Os cenários, apesar de um ou outro estudo com foco na educação básica e no ensino fundamental, priorizaram o ensino técnico e o superior. Mais especificamente, podemos observar que com o avanço de tecnologias digitais a utilização de imagens esteve como objeto de pesquisa em um maior número de publicações (Figura 3). Todavia, também pode-se observar o acréscimo de outras ferramentas metodológicas que se intensificaram nos últimos 10 anos como, por exemplo, ambientes virtuais, modelagens, aplicativos (incluindo software), dispositivos móveis, realidade virtual, gameficação, mapas conceituais e metodologias ativas (diversas).

Além disso, pode-se notar a presença da utilização das tradicionais peças anatômicas, desenhos, dissecação e cadáveres são constantes ao longo do tempo, apresentando uma singela redução para utilização de cadáveres nos últimos anos. 
Figura 3 - Número de publicações e ferramentas metodológicas distribuídas no período de 1970 a 2020 relacionadas ao ensino de Anatomia Humana.

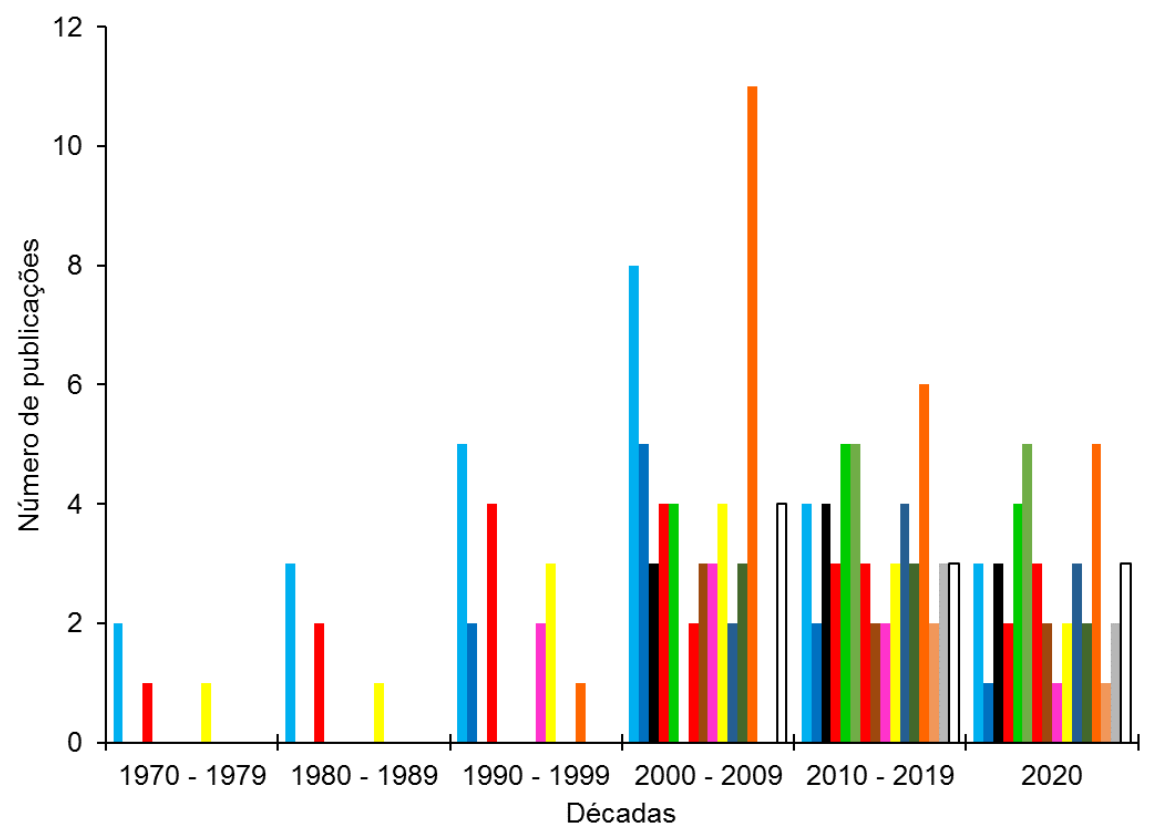

\author{
- Peças Anatomicas \\ - Desenhos \\ - Ambientes Virtuais \\ - Cadáveres \\ Modelagem \\ - Aplicativos \\ - Dispositivos móveis \\ - Realidade Virtual \\ - Pesquisa Empírica \\ Dissecação \\ - Gameficação \\ - Artes Cênicas \\ - Imagens \\ - Mapas Conceituais \\ Metodologia Ativa \\ 口Vídeo Aulas
}

Fonte: Elaborado pelos autores (2021)

Destas publicações, a utilização de peças anatômicas e os Ambientes Virtuais de Aprendizagem (AVA) foram as metodologias mais avaliadas e empregadas como ferramentas de ensino, perfazendo um total de $14 \%$ e $13 \%$ das publicações avaliadas, respectivamente. Em contrapartida, a realidade virtual e vídeo aulas foram as menos avaliadas e empregadas como ferramentas de ensino ( $3 \%$ e $2 \%$, respectivamente) (Figura 4).

Figura 4 - Percentual de ocorrência das ferramentas metodológicas utilizadas pelas 179 publicações avaliadas no período de 1970 a 2020 relacionadas ao ensino de Anatomia Humana.

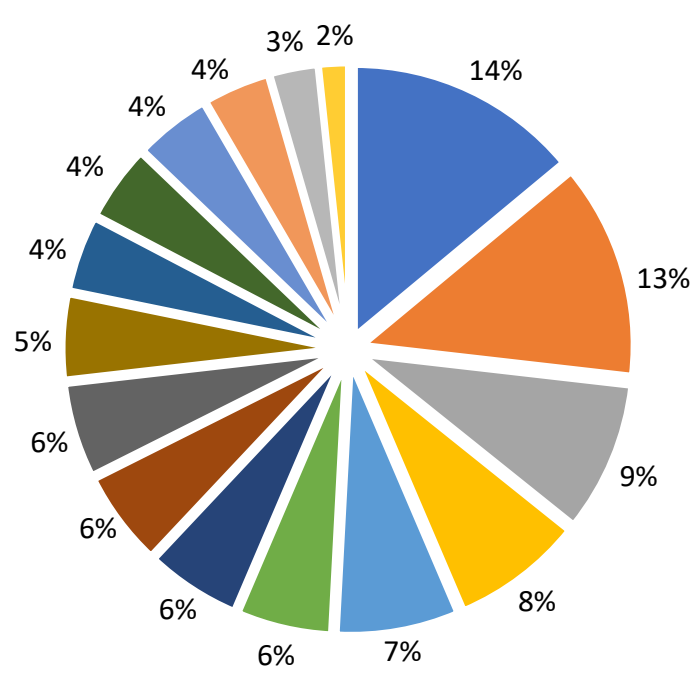

- Peças Anatomicas

- Ambientes Virtuais

- Aplicativos

- Artes Cênicas

- Cadáveres

- Desenhos

- Dispositivos móveis

- Dissecação

- Gameficação

- Imagens

- Mapas Conceituais

- Metodologia Ativa

- Modelagem

- Pesquisa Empírica

- Realidade Virtual

- Vídeo Aulas

Fonte: Elaborado pelos autores (2021) 


\section{Discussão}

O ensino de Anatomia Humana visa compreender as estruturas que compõem o corpo humano. E durante anos, seu ensino tem se pautado em exposições teóricas que pouco interagem com os alunos, levando a monotonia e ao desinteresse. Aliado as aulas expositivas, estão as demonstrações práticas que fazem uma dupla clássica no processo de ensino-aprendizagem em diversos cursos de graduação. No entanto, em outras esferas, como na educação básica e no ensino fundamental, o panorama é outro. E, desta forma, cabe ao professor criar uma aula mais atrativa, inserindo maior dinamismo a suas atividades. Neste sentido, podemos observar com os resultados desta pesquisa o avanço significativo na criação de propostas metodológicas que facilitem a práxis docente e o processo de ensino-aprendizagem. É notória a criação e ampliação das propostas metodológicas para o ensino aliadas ao avanço da tecnologia que sem dúvida contribuiu para alavancar o progresso no processo de ensino-aprendizagem (COLARES et al., 2019; BOFF et al., 2020). Nos últimos anos, tem-se observado a disseminação e utilização das metodologias ativas no ensino em todos os níveis da educação (KFOURI et al. 2019). Essa diversificação nas metodologias de ensino está relacionada ao avanço tecnológico vivenciado atualmente.

A importância da utilização de metodologias de ensino para o aprendizado de Anatomia Humana nos cursos da área da saúde, em especial na graduação em Fisioterapia, foi evidenciado em todos os artigos avaliados. Dentre os tipos de abordagens realizadas, é possível destacar a utilização de peças cadavéricas, que mesmo não sendo o objeto de estudo de algumas pesquisas, é quase unânime sua utilização como o método de ensino, empregado em maior frequência durante as aulas. Em todas as décadas analisadas aqui, a utilização de peças anatômicas, cadáveres e dissecação são metodologias que não podem faltar a esta disciplina. Segundo Costa, Costa e Lins (2012) 88,9\% dos estudantes "consideraram seu uso indispensável nas aulas de anatomia", apesar de outras literaturas apontarem ser um empecilho para alguns estudantes, mesmo que em menor escala.

E acerca das possibilidades de ensino com o cadáver humano, destaca-se a realização de dissecação, pois de acordo com Pereira et al. (2014), este método proporciona aos estudantes correlacionar as estruturas com "patologias diversas, procedimentos clínicos e cirúrgicos", pois devido ao realismo, fortifica a prática clínica em conformidade com o aporte teórico. Além disso, técnicas de imagem e resolução de problemas clínicos podem potencializar o processo (COLLIPAL, 2011).

Entretanto, as adversidades sobre esta metodologia também são retratadas. Dentre elas, podemos destacar a utilização do formol (PEREIRA et al., 2013), maturidade emocional dos acadêmicos (COSTA; COSTA; LINS, 2012), a escassez e o bom estado de conservação (ARRUDA; SOUSA, 2014), além do elevado custo financeiro e dificuldade de renovação dos cadáveres e peças (PEREIRA et al., 2014). E por mais que a abordagem tradicional de ensino em Anatomia Humana tenha uma explanação extensa na literatura, novos métodos surgem como ferramenta complementar ao aprendizado, sem o propósito de usurpar a importância do uso do corpo humano. Estas inovações, apresentam-se por meio de alternativas com potencial de baixo custo-benefício, fácil acesso, portabilidade, ilustrações realistas, ferramenta de avaliação e favorecimento a compreensão do objeto de estudo. Estudos apontam que o emprego de múltiplos métodos de ensino melhoram a capacidade de entendimento 
estudantes (FORNAZIERO; GIL, 2003; JOHNSON et al., 2012), pois despertam habilidades e a curiosidade.

Porém, para utilizar uma abordagem que distingue ao convencionalismo, é necessário a extração de um diagnóstico de todo o processo de ensino aprendizagem. Que perpassa as dificuldades enfrentadas pelos discentes, chegando à forma de como o conteúdo é explorado pelo corpo docente. E apesar da pesquisa idealizada por Cardinot et al. (2014), afirmar que para os acadêmicos do Curso de Fisioterapia, o estudo da disciplina de Anatomia Humana é de fundamental importância para atingir a excelência profissional, corroborando com os dados obtidos por Martineli et al., (2019) e Arruda e Sousa (2014), por vezes apresentam desmotivação e não enxergam aplicabilidade clínica no que foi aprendido.

Mas, apesar do reconhecimento da importância por parte dos estudantes, é possível notar um desinteresse em relação a disciplina, que pode estar atrelada a quantidade de trabalhos e de conteúdos abordados em um curto espaço de tempo, são pontos que expressam a vulnerabilidade da aprendizagem, o que gera uma adoção do conhecimento mecânico (ARRUDA; SOUSA, 2014). Estes autores ainda destacam as dificuldades apresentadas pelos estudantes em relação a Anatomia Humana, é devido a disciplina adotar um teor decoreba, ter pouca ou nenhuma correlação clínica, a falta de aplicação clínica e carência de finalidade com a metodologia e didática do professor (ARRUDA; SOUSA, 2014).

Dentre as contribuições tragas pelo corpo estudantil, a adoção de outras abordagens que visem o aprendizado correlacionado a prática clínica e não a memorização das estruturas, além da adoção de mais aulas práticas, como por exemplo, Anatomia Palpatória (ARRUDA; SOUSA, 2014), é um indicativo significativo do que pode ser explorado durante o percurso da disciplina.

Outra metodologia encontrada na literatura foi a utilização de exames de diagnósticos por imagem, pois apresenta importância para realização do diagnóstico clínico, além de subsidiar o tratamento e consequentemente, um prognóstico positivo. Dentre as imagens estudadas, destacam-se a radiografia, tomografia computadorizada e ressonância magnética (SILVA; ALMEIDA, 2019). Porém, para descrever os resultados apresentados, é necessário o conhecimento em Anatomia Humana, mas devido ao tempo dedicado à imaginologia, a compreensão é vulnerável. Partindo de questionamentos superficiais, apresentando carência no aprofundamento da prática, portanto um conhecimento inconsistente (FEITOZA et al., 2019).

O uso de Mapas Conceituais (MC) foi uma das metodologias ativas abordadas por Brito et al. (2017) e SILVA et al. (2018), e nessas pesquisas os estudantes inicialmente apresentaram dificuldades em construir os MCs, onde esta construção inclusive foi apontada como complexa. Porém, apesar dos obstáculos iniciais, essa ferramenta foi descrita pelos docentes, como facilitadora do processo de aprendizagem significativa, pois dá possibilidade de executar correlações que facilitam o aprendizado, além de expor eventuais lacunas do conhecimento adquirido.

De modo geral, os estudos que compõem a amostra, aqui avaliada, demonstraram uma diversidade de tecnologias educacionais e metodologias ativas voltadas ao ensino de Anatomia Humana. E seu crescimento em paralelo com o avanço tecnológico. No entanto, uma pequena fração destes está diretamente direcionada a graduação em Fisioterapia. Em sua grande maioria os estudos apresentam uma abordagem e investigação acerca dos cursos de graduação na área da saúde. O que é compreensível, já que os conteúdos de "Anatomia Humana" são comuns, exceto as 
especificidades de cada curso da área da saúde. Observa-se ainda que a utilização de metodologias como imagens, aplicativos e modelagens surgiram nos últimos 20 anos e tendem a crescer devido a utilização cada vez maior de tecnologias.

\section{Considerações Finais}

Os artigos que compõem a amostra desta pesquisa apontaram uma diversidade de tecnologias educacionais e metodologias ativas voltadas ao ensino de Anatomia Humana. No entanto, uma pequena parcela de estudos foi direcionada ao curso de Fisioterapia. Todavia, em sua maioria, os estudos investigaram propostas de tecnologias e metodologias educacionais, novas e ou adaptadas, aos cursos da área da saúde. Principalmente, nos últimos 20 anos, constatando a importância de inovações constantes no processo de ensino aprendizagem.

Além disso, revelam a escassez de estudos cujo enfoque seja na metodologia de ensino em Anatomia Humana na graduação em Fisioterapia, enfocando as especificidades inerentes a formação acadêmica deste profissional. $E$ este fator corrobora com a carência de diversidade de métodos e técnicas que possuam comprovação científica e com aplicação/replicação dentro do espaço acadêmico.

No entanto, as pesquisas afirmam em consenso, a importância do ensino teórico com aplicabilidade prática, estimulando o raciocínio clínico e aproximando o campo acadêmico da realidade profissional. Fato já relatado em outros estudos, mas maciçamente encontrado nesta análise.

Por outro lado, das abordagens contidas nesta amostra - estas são diversificadas entre si - contendo tecnologias educacionais e o uso do próprio corpo humano. Contudo, apesar do uso de peças anatômicas cadavéricas e dissecações serem pontuadas frequentemente como as metodologias mais comuns aos cursos da área da saúde, propostas inovadoras e de baixo custo, têm ganhando notoriedade, principalmente pela conjuntura de tornar o aluno autônomo do seu próprio conhecimento ao ascender ativamente uma construção sólida.

De modo geral, pode-se concluir que o ensino de Anatomia Humana tem sido alvo constante na investigação e experimentação de novas tecnologias de ensino, acompanhando os avanços da ciência, incluindo tecnologias digitais, principalmente nos últimos 20 anos. E o acréscimo de vivencias durante o processo de ensino aprendizagem com incremento de ferramentas metodológicas distintas tem contribuído para evitar a evasão, falta de estímulo e desinteresse pelos conteúdos.

\section{Referências}

ARRUDA, Rodrigo Moreira; SOUSA, Cintia Regina Andrade. Aproveitamento teóricoprático da disciplina anatomia humana do curso de fisioterapia. Revista Brasileira de Educação Médica, Brasília, v. 38, n. 1, p. 65-71, 2014. Disponível em: https://doi.org/10.1590/S0100-55022014000100009. Acesso em: 26 jan. 2021.

BOFF, Tália Cássia et al. O uso da tecnologia no ensino da anatomia humana: revisão sistemática da literatura de 2017 a 2020. Medicina, Ribeirão Preto, v. 53, n. 4, p. 447455 , 
https://www.revistas.usp.br/rmrp/article/view/169288/166395. Acesso em: 02 abr. 2021.

BRITO, Sherindan et al. Percepção de alunos quanto ao uso dos Mapas Conceituais como estratégia facilitadora para a aprendizagem da Anatomia Humana. Revista Espacios, Caracas, v. 38, n. 2, p. 25-38, 2017. Disponível em: https://www.revistaespacios.com/a17v38n20/a17v38n20p26.pdf. Acesso em: 26 jan. 2021.

CARDINOT, Themis Moura et al. Importância da disciplina de anatomia humana para os discentes de Educação Física e Fisioterapia da Abeu Centro Universitário De Belford Roxo/RJ. Coleção Pesquisa em Educação Física, Várzea Paulista, v. 13, n. 1, p. 95-102, 2014. 20 Disponível https://fontouraeditora.com.br/periodico/home/viewArticle/1092.. Acesso em: 26 jan. 2021.

COLARES, Maria Alice Mendes et al. Metodologias de ensino de anatomia humana: estratégias para diminuir as dificuldades e proporcionar um melhor processo de ensino-aprendizagem. Arquivos do MUDI, Maringá, v. 23, n. 3, p. 140-160, 2019. Disponível em: https://periodicos.uem.br/ojs/index.php/ArqMudi/article/view/51527. Acesso em: 01 abr. 2021.

COLLIPAL, Larre Erika; SILVA, Mella Héctor. Estudio de la anatomía en cadáver y modelos anatómicos: impresión de los estudiantes. Int. J. Morphol, Temuco, v. 29, n. 4, p. 1181-1185, 2011. Disponível em: http://dx.doi.org/10.4067/S071795022011000400018. Acesso em: 26 set. 2021.

COSTA, Gilliene Batista Ferreira da; COSTA, Gilliane Batista Ferreira da; LINS, Carla Cabral dos Santos Accioly. O cadáver no ensino da anatomia humana: uma visão metodológica e bioética. Revista Brasileira de Educação Médica, Brasília, v. 36, n. 3, p. 369-373, 2012. Disponível em: http://dx.doi.org/10.1590/S010055022012000500011. Acesso em: 26 jan. 2021.

COSTA, Gilliene Batista Ferreira da; COSTA, Gilliane Batista Ferreira da; LINS, Carla Cabral dos Santos Accioly. O Cadáver no Ensino da Anatomia Humana: uma Visão Metodológica e Bioética. Revista Brasileira de Educação Médica, Brasília, v. 36, n. 3, p. 369-373, 2012. Disponível em: https://doi.org/10.1590/S010055022012000500011. Acesso em: 31 jan. 2021.

CROCHEMORE, Matheus Gonçalves; MARQUES, Alexandre Carriconde. Disciplina de Anatomia Humana no curso de Licenciatura em Educação Física: considerações de egressos sobre sua relevância para prática docente. Revista Thema, Pelotas, v. 14, n. 1, p. 8-28, 2017. Disponível em: https://doi.org/10.15536/thema.14.2017.828.375. Acesso em: 02 fev. 2021.

FEITOZA, Alonso Átila Pires et al. Tecnologia em radiologia: estudo comparativo do uso de métodos do diagnóstico por imagem no ensino de anatomia humana. Revista 
de Estudos e Pesquisas sobre Ensino Tecnológico (EDUCITEC), Manaus, v. 5, n. 11, p. 210-233, 2019. Disponível em: http://200.129.168.14:9000/educitec/index.php/educitec/article/view/770. Acesso em: 21 fev. 2021.

FORNAZIERO, Célia Cristina; GIL, Célia Regina Rodrigues. Novas tecnologias aplicadas ao ensino da Anatomia humana. Revista Brasileira de Educação Médica, Brasília, v. 27, n. 2, p. 141-146, 2003. Disponível em: https://doi.org/10.1590/19815271v27.2-009. Acesso em: 25 set. 2021.

JOHNSON, Elizabeth O; CHARCHANTI, Antonia V; TROUPIS, Theodore G. Modernization of an anatomy class: from conceptualization to implementation: a case for integrated multimodal - multidisciplinary teaching. Anat Sci Educ. p. 1-13, 2012. Disponível em: https://doi.org/10.1002/ase.1296. Acesso em: 24 set. 2021.

KFOURI, Samira Fayez et al. Aproximações da Escola Nova com as Metodologias Ativas: Ensinar na Era Digital. Revista de Ensino, Educação e Ciências Humanas, Londrina, v. 20, n 2. p. 132-140, 2019. Disponível em: https://doi.org/10.17921/24478733.2019v20n2p132-140. Acesso em: 23 set. 2021.

MARTINELI, Anderson et al. Percepção dos acadêmicos dos cursos da área da saúde de uma Instituição de Ensino Superior acerca da Disciplina de Anatomia e sua influência na formação profissional. Arch Health Invest, Araçatuba, v. 8, n. 7, p. 336341, 2019.2 Disponível em: https://www.archhealthinvestigation.com.br/ArcHI/article/view/3270.. Acesso em: 01 fev. 2021.

OLIVEIRA, Rafael Galista de; WOLKERS, Carla Patrícia Bejo. Aprendizagem da Anatomia Humana: contribuição de um roteiro teórico-prático. Ciência em Movimento, Porto Alegre, v. 22, n. 43, p. 3-13. Disponível em: https://doi.org/10.15602/1983-9480/cm.v22n43p3-13. Acesso em: 01 mar. 2021.

PEREIRA, Davi Farias et al. Ferramenta prática e multidisciplinar de aprendizagemcurso de dissecção anatômica. Revista UFG, Goiânia, v. 15, n. 15, p. 124-130, 2014. Disponível em: https://www.revistas.ufg.br/revistaufg/article/view/48528. Acesso em: 02 mar. 2021.

PEREIRA, Kleber Fernando et al. Utilização de material plastinado em detrimento aos modelos tradicionais: verificação da predileção de alunos de anatomia humana. Arquivos de Ciências da Saúde da UNIPAR, Umuarama, v. 17, n. 2, p. 105-108, $2013 . \quad$ Disponível em: https://revistas.unipar.br/index.php/saude/article/view/5007. Acesso em: 01 mar. 2021.

SILVA, Janice Henriques da et al. O ensino-aprendizagem da anatomia humana: avaliação do desempenho dos alunos após a utilização de mapas conceituais como uma estratégia pedagógica. Ciência e Educação (Bauru), Bauru, v. 24, n. 1, p. 95110, jan./mar., 2018. Disponível em: http://dx.doi.org/10.1590/1516731320180010007. Acesso em: 26 fev. 2021. 
SILVA, Thiago Santos da; ALMEIDA, Igor Duarte de. A radiologia na prática clínica do Fisioterapeuta. Fisioterapia Ser, Rio de Janeiro, v. 14, n. 1, p. 58 -62, 2019. Disponível em: https://www.researchgate.net/publication/341684451. Acesso em: 04 abr. 2021.

STRINI, Polyanne Junqueira Silva Andresen; STRINI, Paulinne Junqueira Silva Andresen; BERNARDINO JÚNIOR, Roberto. Metodologia ativa em aulas práticas de anatomia humana: A conjunta elaboração de roteiros. Ensino em Revista, Uberlândia, v. 27, n. 2, p, 680-697, maio/ago., 2020. Disponível em: https://doi.org/10.14393/ER-v27n2a2020-13. Acesso em: 10 mar. 2021.

VERRI, Edson Donizetti et al. Elaboração de vídeo-aula como ferramenta de complementar de aprendizagem dos discentes da área de saúde do Centro Universitário Claretiano de Batatais. Linguagem Acadêmica, v. 1, n. 1, p. 123-130, $2011 . \quad$ Disponível em: https://web-api-claretiano-edubr.s3.amazonaws.com/cms/biblioteca/revistas/edicoes/6059fe25c0ce6055c496d14f/ 605b6685dbbe5f8e7720e902.pdfhttps://www.researchgate.net/publication/22875162 6. Acesso em: 06 jan. 2021.

Recebido: $16 / 04 / 2021$

Aprovado: $17 / 11 / 2021$

Como citar: QUEIROZ, C. R.; VARGAS, A, B.; PEREIRA, C. A. S. Abordagens metodológicas utilizadas no processo de ensino-aprendizagem de Anatomia Humana nos últimos 50 anos e aplicações aos graduandos em Fisioterapia. Educitec - Revista de Estudos e Pesquisas sobre Ensino Tecnológico, v. 7, e171421, 2021.

Contribuição de autoria:

Caio Ramon Queiroz: Escrita (rascunho original), conceituação, metodologia, investigação.

André Barbosa Vargas: Validação, análise formal, escrita (rascunho original).

Carlos Alberto Sanches Pereira: Administração do projeto, escrita (revisão e edição).

Editor responsável: landra Maria Weirich da Silva Coelho

Direito autoral: Este artigo está licenciado sob os termos da Licença Creative Commons-

Atribuição 4.0 Internacional 